\title{
NARCOTICS AND CRIMINALITY*
}

\author{
Harold Finestone†
}

Of the many controversial aspects of narcotics addiction in this country, perhaps the most emotionally freighted one has been the nature of its relationship to criminality. ${ }^{1}$ This relationship, which has always appealed to popular imagination, has become the focus of even greater attention in these postwar years, as the use of narcotics has spread in almost epidemic proportions among some sectors of our adolescent and young-adult population, and as these youthful addicts, in increasing numbers, have collided with the police for violations of the narcotic drug laws and for other criminal offenses. This recruitment of growing numbers of young persons to the use of narcotics has, indeed, invested the relationship with a novel character, and it is with the exploration of this somewhat recent development that this paper is primarily concerned. To this end, an attempt will be made to explain how narcotics use and criminality came to coincide in the experience of many young narcotics users, how the narcotics use is related to their criminality, and, then, how this relationship typically changes during the career of the individual addict. There will, then, follow a discussion of some conceptions of the relationship between addiction and criminality that have enjoyed wide currency, and an analysis of them in terms of their applicability to the problem of the young addict.

\section{I}

The Uniform Crime Reports ${ }^{2}$ and the data collected in the course of the Chicago Narcotics Survey, $195 \mathrm{I}-53{ }^{3}$ both indicate a trend, in evidence since the early thirties and interrupted only during the war years, towards not only an increasing number of, but also a correspondingly increased involvement of young persons in narcotic drug law violations. Thus, the Uniform Crime Reports recorded 2,648 arrests for narcotic drug law violations in 1932 , which figure rose to 5,014 in 1940 , fell to 1,123 in 1942 , and rose again to 2,807 in $1946,6,546$ in 1949 , and 13,030 (the apogee) in

* Auch of the material upon which this paper is based has been drawn from the Chicago Narcotics Survcy, a study conducted between I95I and I953 by the Illinois Institute for Juvenile Research and the Chicago Area Project, with the financial assistance of the National Institute of Mental Health, United States Department of Health, Education, and Welfare. The writer would like to acknowledge the assistance received in the preparation of this paper from Clifford R. Shaw, Henry MeKay, and Solomon Kobrin, supervising sociologists at the Illinois Institute for Juvenile Research.

†A.B. 1942, M.A. 1943, McGill University. Research Sociologist of a study, The Rehabilitation Process in Reformed Offenders, conducted since 1954 by the Illinois Institute for Juvenile Research and the Chicago Area Project. Research Sociologist, Chicago Narcotics Survey, I95I-53.

I This paper is restricted to a discussion of the relationship between opiate use and criminality. The relationship between cocaine or marijuana use and criminality raises somewhat different and less urgent problems.

${ }^{2}$ FBI, U. S. Dep't of Justice, Unifora Crime Reports for the United States (i932-55).

a Cf. Chicago Police Department, 1934-53 Annual Reports (n.d.). 
1950. The trend from I952 onwards cannot, unfortunately, be inferred from these data, since the basis of reporting arrests for the Uniform Crime Reports was revised and the population base restricted in that year; but even with the revised procedure of reporting, the number of arrests annually reported has never fallen below the figure reached in 1940 . In 1953 , for example, 5,68I arrests were reported. The Chicago Narcotics Survey data clearly reflect the same trend. The annual number of arrests averaged $33^{\circ}$ for the period $1934-38$, rose to 433 in 1939 , declined during the war period, but resurged during the postwar period, rising to 424 in 1946 and increasing annually thereafter until a peak of 1,188 was reported in 1951. The most recent years for which comparable data are available, 1954 and 1955, however, show some tendency towards a diminution in the number of arrests.

Closely paralleling this increase in the absolute number of arrests for narcotic drug law violations is the trend, on both the national level and in Chicago, towards a gradually increasing proportionate number of such arrests in the younger age groups. The data from the Uniform Crime Reports indicate that in I932, the proportion of total arrests for narcotic drug law violations in the twenty-four-and-under age group was fifteen per cent; in I94I, this proportion was twenty-nine per cent; and in $x 95 x$, it was forty-six per cent. The operation of a similar trend in Chicago is revealed by the fact that the proportion of total arrests falling in the sixteen-totwenty age group was four per cent in $1934-3^{8}$, seven per cent in I94I, and twentyfour per cent in both $195^{\circ}$ and $195^{1}$. During the same period, the proportion of total arrests in Chicago falling in the thirty-one-and-over age group decreased from an annual average of fifty-five per cent for the period 1934-38 to twenty-five per cent in 1951. Another method of portraying the same trend for Chicago is through the rates of arrest for narcotic drug law violations in each age group. Table I permits such a comparison.

\section{TABLE I}

Rates of Arrest for Narcotic Drug Law Violations (Chicago) Per 10,000 Population for Different Age Groups During the Periods 1934-38 and I95 I

$\begin{array}{ccc}\text { Age groups } & 1934-38 & 1951 \\ \text { I6-20 } & .43 & 13.64 \\ 21-30 & 2.10 & 10.08 \\ 3 \text { I and over } & 1.09 & 1.48\end{array}$

And still additional evidence of the trend towards the growing recruitment of new narcotics users among young people is provided by the data on first admissions of Chicago residents to the United States Public Health Service Hospital, Lexington, Kentucky, for two separate periods, $1937-4 \mathrm{I}$ and $1947-5 \mathrm{I}$. For the period $1937-4 \mathrm{I}$, the sixteen-to-twenty age group constituted four out of a total of 282 , or I.4 per cent of the first admissions; in the later period, I947-51, it constituted 354 out of 1476 , or twenty-four per cent of the first admissions. In contrast to this younger age group, the thirty-one-and-over age group comprised seventy-two per cent of the total first 
admissions in the period I937-4I, and only twenty-seven per cent of such admissions in the period $x 947-51$.

These data appear unequivocally to evince the changing character of the narcotics addict population, which, since the early thirties, has more and more, both absolutely and proportionately, come to be comprised of adolescent and young-adult age groups.

But what are the types of offenses, apart from narcotic drug law violations, for which these addicts have been arrested? Is there any substance to the common notion that a high proportion of crimes committed by addicts are crimes of violence? The organization of the Narcotic Bureau of the Chicago Police Department in $195^{\circ}$ made possible the collection of data about the arrests of all known narcotics users which sheds some light in this area. From these data for the year I95I, it has been possible to classify these arrests and to determine the percentage distribution of the more serious types of offenses among addicts vis á vis the population at large. These

TABLE II

The Percentage Distributton of Arrests for the Most Sertous Types of Offenses in the Narcotic Bureau and the Chicago Police Department, $1955^{5}$

\begin{tabular}{cc} 
Narcotic & $\begin{array}{c}\text { Chicago Police } \\
\text { Bureau }\end{array}$ \\
58.8 & 31.0 \\
I6.2 & 7.3 \\
9.9 & 9.4 \\
5.1 & 3.2 \\
& \\
4.2 & 4.9 \\
1.6 & II.0 \\
1.5 & 9.1 \\
1.4 & 4.4 \\
1.3 & I9.7 \\
\hline 100.0 & I00.0
\end{tabular}

figures are presented in Table II, and they would seem to indicate that the number of arrests for nonviolent, property crimes was proportionately higher among addicts. In contrast, however, the number of arrests of addicts for violent offenses against the person, such as rape and aggravated assault, was only a fraction of the proportion constituted by such arrests among the population at large.

Another kind of datum that bears directly on the relationship between narcotics use and criminality is that showing the spatial distribution of narcotic addicts within the urban community. Faris and Dunham, in their study of 772 cases of addicts admitted to four Illinois State Hospitals and eight private institutions from the city of Chicago in the period I922-34, observed that there appeared to be a general con-

- Arrests for criminal homicide were not tabulated separately by the Narcotic Bureau, however, because their number was too small to justify a separate category.

- Chichgo Police Departanent, i95i Annual Report i3 (n.d.) 
centration of such cases in and near the center of the city. "It is noted that almost $5^{\circ}$ per cent of the cases are in the hobo and rooming-house areas at the center of the city." Since the period of the Faris and Dunham study, the character of the addiction problem has been changing in the direction indicated in the previous discussion, but ecologically, the incidence of addiction has remained heavily concentrated in a few of the disadvantaged areas of the city: ${ }^{7}$

The drug use problem is concentrated with extraordinary sharpness in a very limited segment of the city's population. ... Almost two thirds of Chicago's drug users may be found in the decile, or tenth, of the population whose community rates [of drug users by community areas] are the very highest. Almost nine of every ten drug users may be found in the upper deciles, representing 20 per cent of the city's population.

And other types of data indicate that where the incidence of addiction is highest, there is the heaviest concentration of many other types of social problems: ${ }^{8}$

The highest concentrations of drug users are found in the communities displaying the highest rates of Juvenile Court delinquents, of Boys' Court cases, of tuberculosis, and of infant mortality. These are the communities of lowest income in the city.

Similar findings concerning the ecology of narcotics addiction in New York City were established in recent studies conducted by the Research Center for Human Relations, New York University. ${ }^{9}$ This agreement in the findings of these recent studies, together with the observation that the distribution of many deviant social phenomena has tended to exhibit a similarity in spatial pattern in many other ecological studies, affords some basis for the tentative hypothesis, here advanced, that the findings of the Chicago study may also apply to other large cities where there is a problem of narcotics use among young persons.

A comparison of the distribution of cases of narcotics addiction in the Faris and Dunham study with the distribution of cases in the Chicago study almost a generation later reveals a definite relationship between the two. In the earlier study, as has been noted, the cases were concentrated in and near the center of the city, in the hobo and rooming-house districts, which were part of the "zone of transition." The more recent Chicago study established that the cases were concentrated in the disadvantaged areas farther out from the center of the city, but immediately adjoining the "zone of transition." The change from the earlier to the later pattern of distribution involved no spatial discontinuity-that is, the new areas of concentration were immediately contiguous to the areas where the problem was formerly most highly concentrated-and this suggests that narcotics use may have diffused from one area to the next.

\footnotetext{
${ }^{\circ}$ Robert E. L. Faris and H. Warren Dunham, Mental Disorders in Urban Areas 122 (1939). ${ }^{7}$ Illinots Institute for Juvenile Research and the Chicago Area Project, Report of the ChICAgo NarcotIcs SuRvey 44 (unpublished manuscript I953).

${ }^{8}$ Illinois Institute for Juvenile Research, Drug Addichon Amonc Young Persons in Chichco 6 (1953).

${ }^{\circ}$ For a brief description of the nature and scope of these studies, see the bibliography appended to Chein and Rosenfeld, Juvenile Narcotics Use, supra 52-68.
} 
In the light of these data, let us now address the central problem of the relationship of narcotics use and criminality: How did narcotics use and criminality come to coincide in the life experierice of many adolescents and young adults in the disadvantaged areas of large cities, such as Chicago? What is the nature of the relationship between the narcotics use and criminality in this sector of the population? The central theme of the interpretation to be offered is that this conjunction has been, in part, a consequence of influences having their origin in the social life, or "subculture," of these young persons and, in part, a consequence of influences having their origin in the local communities which impinge on the young persons residing there.

In spreading to young persons, as it did, narcotics use made its inroads within a distinctive and uniquely vulnerable social milieu, the world of the adolescent in the most disadvantaged areas of the city. Like their age-mates everywhere, these adolescents spontaneously form peer groups, which exert a significant influence upon their conduct. In other types of communities, however, particularly those of higher socioeconomic status, the control over behavior exerted by the peer group is subject to restraint by the obligations and loyalties binding the individual adolescent members to other conventional groups, such as the family and the school. By way of contrast, such competing obligations and loyalties fail to exert their limiting and moderating influences in the most disadvantaged areas, and the peer group assumes a virtually sovereign control over the behavior of the individual adolescent. Under such conditions, the introduction of a novel practice may lead to its rapid diffusion, and, because it is unchecked by pressures counter to those exerted by the peer group itself, go to extremes that are not possible among adolescents elsewhere. In this milieu, narcotics use could spread more selectively and with somewhat greater difficulty, perhaps, but in a manner analogous to a new fashion in language, dress, or music.

The social world of the adolescent male in the disadvantaged areas has been aptly characterized by the term "street-corner society." This concept, which will be referred to frequently in the subsequent discussion, has been developed as follows: $:^{10}$

This term has come into use in recent years to describe the street gangs which abound in certain quarters of the city. The use of the expression "society" in connection with such gangs is meant to suggest that all members of street gangs share a distinctive set of ideas and attitudes, much as would, say, the members of "cafe society." It is, moreover, a society in the sense that a large enough number of young persons have participated in it over a long enough period of time so that it exists independently of particular persons entering or leaving its ranks.

This society flourishes in those communities where the traditional influences and controls over the conduct of the youth group tends to be weak and uncertain. In such communities all young persons either participate in or are exposed to the activities of this society. In the face of counteracting pressures for conformity to the rules and morals of the wider society, of varying degrees of effectiveness, some youngsters merely dabble in

\footnotetext{
${ }^{10}$ Ili.inois Institute for Juvenile Research, op. cit. stipra note 8, at 9-10.
} 
street society, taking on only some of its superficial traits; others participate fully but for relatively short periods; and still others become full-fledged members and ultimately the bearers and agents of its code and its culture.

The central feature of this society and its body of practices, or "culture," is the support it gives to behavior which is generally inconsistent with the norms of conventional society, and often openly hostile to many of its expectations. This orientation on the part of street boys is expressed in a variety of ways, but is most clearly and dramatically manifested in delinquency, and in the search for and exploitation of "kicks."

It is evident from this description that there are significant influences originating in street-corner society itself that would be hospitable to experimentation with narcotics. An orientation to life which gives zestful sanction to many forms of unconventional activity appears to have spread the welcome mat for narcotics use. Much of the behavior reported by these young addicts clearly indicates that they had actively sought out narcotics-and not only heroin, but every other substance of which they had heard which yielded a "kick," such as marijuana, cocaine, benzedrine, and the barbiturates. The activity centering around these narcotics had many of the characteristics of a fad-that is, the restless searching, the uncertainty and excitement and exclusive preoccupation with a novel experience, the pressures to "go along," and the final capitulation on the part of many, despite the existence of strong initial doubts and inhibitions.

While the spread of narcotics use to young persons was tightly restricted to those local areas which also had high rates of juvenile delinquency and young-adult criminality, there were some communities with rates of juvenile delinquency almost as high where adolescent narcotics use was virtually unknown. In a community of the latter type, it was actually possible to observe a situation where the coming to light of several cases of narcotics use by young people of the locality evoked such strong moral disapproval and community resistance that any potential epidemic was quickly averted in its incipient stages. By way of contrast, in many of the areas to which narcotics use spread, the local residents were just as morally aroused, but their opposition was ineffective. In the first type of local community, the local residents were capable of collective action to insure effective law enforcement and other direct measures to deal with the problem; in the latter type of community, the local residents were not able to turn their strong moral disapproval into effective collective action.

This discussion suggests that narcotics use spread to adolescents in communities deficient in two essential types of social control: first, the controls originating in conventional institutions which define the limits of permissible behavior for adolescents; and secondly, the controls by means of which the community is enabled to resist encroachments by those espousing values to which it is strongly antagonistic. These deficiencies constitute an essential part of the "slum-making process." It was apparently the operation of similar processes that led to the concentration of such deviant occupational types as criminals, racketeers, prostitutes, and drug peddlers 
in the same disadvantaged areas in which narcotics use was later to spread among young people. The location of such aberrant types in these areas is fraught with significance, because in time they come to symbolize both opportunity and hazard for many street-corner boys.

In view of the weakness of community solidarity in the disadvantaged areas, the location there of such deviant types is not to be construed as an expression of the moral qualities of the local residents, but rather as part of a process of selection whereby these types locate where they can survive and perform their function. Although at first an alien influence in the slum community, these deviant types do, however, in time attract local, and particularly younger, residents to perform their illegal functions. Lohman has commented upon a similar process in his observation of the consequences of the location of gambling and prostitution in the Near North-Side Communities of Chicago in the late thirties:11

... Occupational opportunities are limited in character. The first and foremost facet for the gaining of a livelihood which competition in the whole life of the city assigns to communities such as the Italian or the Negro on Chicago's Near North Side is of course unskilled labor. The low income standard which such work provides stands in strong contra-distinction to standards of success and personal property which society at large exhibits. On the other hand, the community has, within its environs, pursuits which afford a higher income. These opportunities may not in themselves be morally approved by conventional society but the whole society gives rise to their being and they singularly afford what other limited laboring opportunities deny.

The location of such institutions of vice and disorganization, through the impersonal distribution of function throughout the city has established an order to which the local community subscribes. The shills, stickmen, dealers, doormen, in short, the professional staff of C-Street's bookies and gambling resorts are provided largely by the local community to the west. Prostitution along D-Street, with the first invasion of the Colored community supplied largely by recruited inmates from the south side, is now a matter entirely of local occupation not only for the girls, but for the operators as well. . . .

In the localities frequented by adult criminals, the notoriety, glamor, and symbols of material success that are sometimes associated with them enhance their attractiveness as role-models to members of street-corner society, who, as adolescents, may find it easier to identify with them than with conventional role-models. In a similar vein, interviews with young narcotic addicts in 1952 suggested the observation that in at least certain social circles where these youngsters sought status and recognition, adult addicts or "junkies" enjoyed a certain prestige. Many of these young addicts reported that they and others had tried to simulate the mannerisms and philosophy of life of addicts before they themselves had become addicted.

Reverting now to the relationship between narcotics and criminality, the principal observation to be made is that narcotics use spread to adolescent groups who simultaneously evaluated highly adults who were engaged in a wide variety of (1937).

${ }^{11}$ Lohman, The Participant Observer in Community Studies, 2 AM. Socrologicar. Rev. 890, 894 
criminal activity and adults who were addicted; and these valuations were reflected in both criminal activity and experimentation with narcotics. Thus, both the criminality and experimentation with narcotics stemmed, at least in part, from influences to which the youngsters were exposed, as represented by adult models within the local community. Both criminality and narcotics use came to be prestigeful forms of activity. In this sense, it is irrelevant to ask whether the delinquency preceded the addiction or vice versa. Many of those who became addicted and were forced to engage in crime to support the high cost of their addiction would probably have gone on to engage in crime as adolescents regardless of whether or not they had become addicted.

The statement that both delinquency and narcotics use existed side by side as independently valued patterns of behavior is not inconsistent with the observation that for specific individuals, delinquency or narcotics use may have initially represented alternative forms of behavior. ${ }^{12}$ Nor is it inconsistent to observe that each activity became modified within the individual's behavior when conditioned by the other. For example, in some instances, adolescents on the fringes of street-corner society and only marginally involved in criminal activity apparently seized on the possibility of narcotics use as a means of enhancing their status in the group, since it was not always the existing leaders who were the first to experiment with narcotics. Once addicted, however, these adolescents, who previously had been only marginally involved in delinquency, were forced into regular criminal activity in order to raise money to maintain their supply of narcotics.

What kind of image can be formed of the young addict or "junky" and of his milieu that may be of assistance in understanding the relationship between narcotics use and crime? At the time when many of these young addicts were interviewed in I952, most were still in the early stages of their addiction. They were "snatch-andgrab" junkies, supporting their habits through petty thievery, breaking into cars, shoplifting, and a variety of "scheming," such as "laying a story" on "a sucker" in the hope of gaining sympathy and some cash. Some enterprising ones actually had girls out "hustling" for them through "boosting" (shoplifting) and "turning tricks" (prostitution). Despite the ragged state of their clothing and the harried nature of their existence, they regarded themselves as the members of an elite, the true "down cats" on the best "kick" of them all, "Horse" (heroin). Many of them were still living at home, although they had long since exhausted the last reserves of patience of their families and "fenced" much of their movable property. Few, if any, of them had finished high school, and, on the average, they had little or no employment experience. Their attitudes towards work and the daily routine that steady employment presupposed were entirely negative. Their number-one hazard was the "man" (the police). Once they became "known junkies"-that is, known to the policethey were frequently picked up and sometimes sentenced-mostly for misdemeanors

${ }^{20} \mathrm{Cf}$. Dumpson, Gang and Narcotic Problems of Teen Age Youth, 6 AM. J. PsychothrRAPY 312 (1952). 
and, consequently, for short sentences. In their own words, they would begin to "ride the horse to California" (in Chicago, the criminal and narcotic courts, as well as the County Jail and the House of Correction, are located on the street with this name). The police became a symbol of the "revolving door through whose entrance and exit the same persons form a constant procession."13

After months and sometimes years of this kind of existence, the morale of the young junky drops very low, or his health deteriorates, or his daily requirement of narcotics gets beyond his ability to support, and he finally considers attempting to cure himself of the habit. Because these addicts were constantly being picked up by the police and held at the police lockup or receiving short sentences, they were frequently forced to "kick the habit cold turkey"-that is, to undergo the abrupt withdrawal of the narcotic. This would remove their physical dependence on it, but they would inevitably relapse shortly upon release. Consequently, when they sought a "cure," they hoped for more than mere withdrawal of the narcotic. At this point, their motivation was never clear, but it led many of them to seek treatment at the United States Public Health Service Hospital at Lexington. The treatment at Lexington, too, was very frequently followed by relapse.

The question arises as to the relationship of the young narcotics addict to the rest of the criminal world. The impression gained from interviewing them was that these addicts were petty thieves and petty "operators" who, status-wise, were at the bottom of the criminal population or underworld. It is difficult to see how they could be otherwise. The typical young junky spent so much of his time in a harried quest for narcotics, dodging the police, and in lockups, that he was hardly in a position to plan major crimes.

It is to be observed that narcotics use spread to areas and to parts of the city and to groups of adolescents and young adult males who have traditionally been responsible for a high proportion of the larceny and robbery and other serious property crimes committed in the city. Accordingly, it would be expected that a certain proportion of young addicts would also be responsible for these major offenses. This was found to be true, but the interviews suggested two further relevant observations: First, a number of addicts did commit serious offenses against property and persons, but usually such individuals had also committed similar offenses before becoming addicted. Second, the number of offenses coupled with violence appeared to be but a small proportion of the total, an observation which is corroborated by the data from the Narcotic Bureau of the Chicago Police Department for 195x, presented earlier. Addiction, thus, appears to reduce both the inclination to violent crime and the capacity to engage in sophisticated types of crime requiring much planning.

If the present public policy towards addiction remains unchanged, it is a moot question as to what will happen to these young addicts as they grow older. It seems unlikely that they can rise in status among their nonaddicted associates who

${ }^{18}$ Collins, Law and the Woman Narcotic, in Proceedings of the Sixty-Seventh Annual Congress of the American Prison Ass'n 66, 68 (1937). 
are engaged in criminal activity, nor are they likely to become engaged in more serious types of crimes. The possibility that most plausibly suggests itself is that as they grow older and wiser in the ways of coping with their addiction, they will increasingly learn to "cool it"-that is, they will leave behind them the days of the "frantic" and the "snatch-and-grab" junky and learn to conceal their addiction. Through trial and error, they will grope for unconventional and illegal ways of making money that will involve a minimum of risk-taking. They will also learn to take the occasional "bust" and short sentence. As public concern over the problem of narcotics use falls off, many will find ways and means of establishing a modus vivendi with the police. And, although the evidence for this is obscure and inconclusive, some few of them may be able to "kick the habit" for relatively long periods of time and achieve some semblance of conventional life. Those few engaged in serious criminality will probably continue to engage in it. For them, penitentiaries rather than the House of Correction or the County Jail will punctuate their sojourn on the streets.

What, finally, are the implications of the spread of narcotics use to street-corner society? One of the most intractable features of that society is its detachment from conventional institutions and controls and its opposition to social expectations having their origin in the conventional world. This detachment represents the greatest obstacle to any attempted intervention to modify the behavior of its members. The spread of narcotics use to this segment of the community has increased its sense of alienation and has intensified the difficulties of effective intervention. These young addicts have come increasingly to live in a world apart, and all their experiences are such as to make them, realistically, increasingly unemployable as times goes on. This alienation of the young junky, this widening spatial and social distance separating him from the conventional sectors of the community and of public opinion, has, unfortunately, by making his behavior so apparently unintelligible, further tended to reinforce the common stereotype of the "drug fiend." Such stereotypes have impeded more humane and realistic measures to cope with the plight of the young addict.

Observers have expressed surprise at the metamorphosis by which the streetcorner boy evolves into the young adult who becomes a hard-working conventional, family man. This transformation takes place despite the occasional handicap of a juvenile or adult criminal record and the stigma of being an "ex-con." It is a transition that can be explained, at least in many cases, as a change from the adolescent to the adult role. The adult male has occupation and family as incentives for him to achieve a stable life organization. The adolescent, particularly in the disadvantaged areas, often does not have such powerful incentives until he reaches young adulthood. It has been noticed that young addicts, as they near adulthood, sometimes attempt to re-evaluate their modes of behavior, including their addiction, from an adult perspective and even make some gestures to achieve a conventional adult 
role. Rarely does it get beyond the stage of gesture, however, because of the demands of their addiction. The spread of narcotic use to street-corner society, thus, has had the effect of perpetuating petty criminal careers which otherwise might have been merely an episodic part of the individual's life as an adolescent and as a street-corner boy.

II

Having observed the setting in which narcotics and criminality become associated in the experience of young persons, let us turn brielly to two currently prevalent conceptions of this relationship and discuss their applicability to the problem of the young addict. These two conceptions, representing, in general, the perspectives of the two groups of officials most directly responsible for dealing with the addict-the law enforcement and medical authorities-may be designated as the correctional and the medical points of view, respectively. Since each of the two conceptions is intelligible only when considered in relation to present public policy, which it is in part, intended to implement, a few of the immediately relevant features of this policy should be explored.

The present policy, implemented, with a few unimportant exceptions, through the Harrison Act, ${ }^{14}$ enforces the prohibition of all narcotics for the satisfaction of addiction. Since, at the time of its inauguration, there was a sizeable addict population-the most generally accepted estimates of their number made at this period being in the neighborhood of $100,000^{15}$-this prohibition policy apparently assumed that total abstinence was a feasible goal for all addicts. This assumption has, in fact, become the basis for most subsequent discussions of the problem of addiction in this country. In 1932, Treadway stated the prevailing view as follows: ${ }^{16}$

The necessity of prolonged or life-long administration of narcotic drugs is not universally held in this country. . . . According to the modern conception, crystallized in socially and legally sanctioned laws, drug addicts or persons requiring continuous and nondiminishing doses of opium or its derivatives are unpopular and regarded as a menace to the social order. They appear to constitute a medicosocial problem demanding institutional segregation and treatment. There is, however, no treatment for drug addiction from the standpoint of specific cure that will miraculously operate to rid drug addicts of their addiction.

The adoption of this policy confronted every addict with the dilemma of either seeking to cure his addiction or violating the law and, thus, exposing himself to criminal prosecution, conviction, and incarceration. The fact that many thousands chose the latter course, despite the threat of imprisonment and the destructive personal and social consequences of addict status, raises some question as to the practicality of a policy that attempts to enforce total abstinence on the part of addicts. The

${ }^{14}$ Act of Dec. 17, xg14, c. I, 38 STAT. 785, as amended, 26 U. S. c. $\$ \$ 470 x-36$ (Supp. III, r956).

${ }^{15}$ See Kolb and Du Mez, The Prevalence and Trend of Drug Addiction in the United States and Factors Influencing It, 39 PuBlic HeALth ReP. r179, 1202 (1924).

${ }^{10}$ Treadway, Drug Addiction and Measures for Its Prevention in the United States, 99 A. M. A. J. 372,376 (1932). 
issue is further complicated in this country by the availability, through nonmedical channels, of illicit narcotics at highly inflated prices.

The problems confronting physicians who attempt to treat the addict under this public policy of prohibition have led to certain additional assumptions as to the relationship of narcotics and criminality. Lambert, a prominent physician concerned with the treatment of addicts, has articulated these assumptions in the following terms: ${ }^{17}$

It is clear that the individual who is a criminal and has been convicted for misdemeanors or felonies is a far different person to deal with than the individual who is convicted of the single misdemeanor of being in possession of one of these drugs.

Many difficulties arise as a result of treatment because of the differences between these two main groups, and there are also greater difficulties in the general problem of the rehabilitation of the drug addict after the successful withdrawal treatment.

This early distinction between types of addicts raises the two issues which have become central to all subsequent discussion on the relationship between narcotics and criminality: First, should violators of the Harrison Act be considered criminals in the same sense as violators of other laws; or should they be regarded as criminals in a merely technical sense? This issue is joined specifically in the case of the addicted narcotic drug law violator. Second, should addiction be regarded as an extenuating factor in other criminal cases, or is it merely additional evidence of the dangerous character of the offender? Sometimes this latter issue has seemed to turn on whether the criminality or the addiction was the prior event in the life career of the typical addict. For those holding that criminality generally precedes addiction, addiction is regarded as incidental and not a problem separate from criminality. Conversely, those holding that addiction is usually the antecedent event tend to regard criminality as a by-product, compelled by the necessities of supporting the addiction, that will automatically be eliminated if a successful cure of addiction is achieved.

In approaching these and other closely related issues, the correctional and medical perspectives are diametrically opposed. The former emphasizes the gravity of the problem of criminality associated with addiction and assumes that for the generality of addicts, criminality is prior in time to addiction, which is regarded as merely another incident of an antisocial attitude towards life. It, thus, tends to reduce the whole problem of the relationship between narcotics use and criminality to one of criminality. In reference to narcotic drug law violations, it draws little or no distinction between the addicted and the nonaddicted offender. Some aspects of this philosophy are illustrated in the following passage from the annual report for r938 of the Federal Bureau of Narcotics, a leading proponent of the correctional point of view: $:^{18}$

${ }^{17}$ Lambert, Report of the Mayor's Committee on Drug Addiction to the Hon. Richard C. Patterson, 7r., Commissioner of Correction, New York City, 87 AM. J. Psychintry 433, 435 (1930).

${ }^{18}$ Bureau of Narcotics, U. S. Treasury Dep't, Traffic in Opium and Other Dangerous Drugs 6, 7 (1939). 
The overwhelming majority of narcotic drug addicts which [sic] have come to the attention of the authorities recently in the United States belong to the criminal element, and for various reasons it has been considered important to ascertain at what stage of their careers these individuals entered upon the drug addiction habit. In a study now being made of a considerable group selected at random from the records it has been learned that the first arrest for offenses other than narcotic law violations preceded, sometimes by as much as 8 to ro years, the year when narcotic drug addiction began. . . .

From the present study, it can definitely be concluded that drug addiction is one of the later phases of the criminal career of the addict rather than a predisposing factor. The procession of events is from criminality to addiction, or from defective personality to criminality to addiction.

Consistent with this conception of the relationship between narcotics use and criminality, the correctional perspective advocates vigorous police activity against the addict: $:^{10}$

In addition to suppressing the traffic in narcotics, police activity against drug addicts is a very essential part of general police operations. The great majority of addicts are parasitic. This parasitic drug addict is a tremendous burden on the community. He represents a continuing problem to the police through his depredations against society. $\mathrm{He}$ is a thief, a burglar, a robber; if a woman, a prostitute or a shoplifter. The person is generally a criminal or on the road to criminality before he becomes addicted. Once addicted he has the greatest reason in the world for continuing his life of crime. Most policemen recognize that one of the best ways to break up waves of pocket-picking, petty thievery and burglary in a community is by making a round-up of the narcotic addicts. Often, a long term of imprisonment for a narcotic addict on narcotic charges will rid the community of a burglar or thief for that period.

Within the field of correctional practice during the present century, however, there has been a dual emphasis upon both punishment and rehabilitation as the goals of correctional treatment. Historically, punishment is the much older philosophy, and it has only been with the increasing recognition of naturalistic and causal interpretations of human behavior, a comparatively recent development, that the emphasis upon rehabilitation has made headway. At first applied only to juvenile offenders, this latter philosophy has gradually been extended to criminal offenders of older age groups as well. It is also a philosophy that has application at all stages in the administration of justice and in correctional institutions. The crucial question here is whether it could not in much greater measure than is now the case also be extended to this peculiar offense-narcotics addiction. The high rate of recidivism among violators of the narcotic drug laws has frequently been observed. Is this not an illustration of the futility of mere punishment? There is, undoubtedly, a certain logic to present police methods, because there is no denying that a high proportion of young addicts engage in crime-in most cases, almost daily-to support their habit. Since a cure, if it is to be achieved at all, is most likely to be achieved in the earlier stages of addiction, however, it may well be asked whether the current correctional

${ }^{10} \mathrm{H}$. J. Anslinger and W. F. Tompkins, The Traffic in Narcottcs I7o (1953). 
approach might not be more successful were it to place greater emphasis upon rehabilitation.

Another germane consideration is the interpretation that has been given of the manner in which narcotics addiction has spread to young persons. It was an explanation, hypothetical and yet seeming to square with the facts, that pointed to the significance of many social influences in the milieu of the young addict. Such an explanation suggests that the young addict presents an appealing case for intervention and rehabilitation. It does not suggest which course such effort should take, but it does indicate and locate the malign influences that must be countered if rehabilitation is to have any chance of success.

In contrast to the correctional, the medical perspective minimizes the extent and seriousness of the criminality associated with addiction. In the typical case, it believes that the addiction is the antecedent factor and the criminality merely one of its consequences. It draws a sharp distinction between addicted and nonaddicted violators of the narcotic drug laws, contending that the former should not be regarded as criminals. Speaking from this point of view and the perspective of his "statistical analysis of the information contained in the clinical records of 1,036 patients admitted for the treatment of narcotic drug addiction to the United States Public Health Service Hospital, Lexington, Kentucky, during the fiscal year, July I, 1936 to June 30, I937," Pescor makes the following observations about the relationship between addiction and criminality: $:^{20}$

If the addict is basically a criminal, it is likely that he would have committed antisocial acts prior to his addicton; yet three-fourths of the patients had no delinquency record prior to addiction. In arriving at this finding, arrests without any subsequent punitive action were not counted, since presumably the patients were not guilty if the charges were dropped. About one-fourth of the patients admitted delinquencies, with misdemeanors heading the list, convictions second, and juvenile offenses third.

A substantial majority of the patients were not antisocial prior to addiction, but a large number became antisocial after addiction for two principal reasons: First, with certain exceptions, the possession of drugs in itself constitutes a violation of the law. Second, the high cost of bootleg drugs practically forces individuals of marginal economic status to resort to illegal sources of income, usually through the sale of narcotics or larceny. ...

Analysis of the problem along these lines has led the spokesmen for the medical perspective to regard addiction as a public health problem and the addict as a sick person to be treated medically. Kolb has amplified these points as follows ${ }^{21}$

The drug addict is a much misunderstood individual. He is a problem, but not so great a problem as he is generally supposed to be; and he does commit crimes, but not to the extent which is generally believed. . . .

.... Chronic addicts suffer some slight physical deterioration because of the direct effect of the drug. They suffer more character deterioration because of the physical

${ }^{20}$ Pescor, A Statistical Analysis of the Clinical Records of Hospitalized Drttg Addicts, 43 Pubutc HeALTh ReP. 6 (1938).

${ }^{21}$ Kolb, The Narcotic Addict: His Treatment, Fed. Probation, Aug. 1939, pp. 19, 20. 
enslavement that makes them feel inferior, because they must neglect work in order to search for narcotics; because they are impelled to become parasites and thieves in order to keep up their supply; because, for the same reason, they must associate with questionable characters and always be trying to avoid law officers; and lastly because they evade responsibility and solve all difficult problems by narcotizing themselves.

And again:22

It is important that the public be informed as to the exact importance of drug addiction in its relation to other things, so that the addict may be regarded not necessarily as a criminal, but as a sick person, who needs more attention from the physician and less from the police.

This conception of the addict as a "sick person" has been" given a new dimension in the work of the psychiatrists, who have defined addiction as a symptom of personality difficulties: ${ }^{23}$

.... drug addiction is not in itself a disease, but rather a manifestation or symptom of an individual's personality difficulties. Kolb has said that the addict is a psychologically maladjusted individual, plus an accident, the latter being his introduction to a narcotic.

In considering the applicability of the medical perspective in this area, however, two points must further be elaborated: first, the present policy which restricts the medical treatment of addicts to an institutional setting; and, second, the conception of addiction as a symptom of personality difficulties.

At the present time, the only setting in which physicians can treat addicts is within institutions, such as the United States Public Health Service Hospitals at Lexington, Kentucky, and Fort Worth, Texas. Any type of bona fide physicianpatient relationship for the treatment of addiction in the community is not permissible under the present administration of the Harrison Act. Since, however, any advance in the treatment of addiction must come from the medical profession itself, it may legitimately be asked whether present public policy conduces this end-does it permit the profession to become sufficiently familiar with the problem of addiction so that basic contributions to the knowledge and treatment of addiction can reasonably be expected from it. Moreover, one of the implications of the earlier discussion of the milieu to which narcotics use has spread would seem to be that intimate familiarity on the part of the physician with the values of the young addict from street-corner society would be a necessary condition for an effective, dispassionate physician-patient relationship.

The role of the medical profession in relation to the problem of addiction was examined by Dr. Herbert Berger, Vice-President of the Medical Society of the State of New York, in testifying at the hearings of a subcommittee of the Committee on Ways and Means of the House of Representatives in November 1955, as follows: ${ }^{24}$

${ }^{22} \mathrm{Kolb}$, Drug Addiction as a Public Health Problem, 48 Scientific MonTrLY 39r, 400 (1939).

${ }^{23}$ Felix, An Appraisal of the Personality Types of the Addict, roo Am. J. PsychInTRY 462, 465 (1944).

${ }^{24}$ Hearings Before the Subcommittee on Traffic in, and Control of, Narcotics, Barbiturates, and Amphetamines of the House Committee on Ways and Means, 84th Cong., 2d Sess. 663 (1956). 
Are there any experts in narcotic addiction in the medical profession? I would say those that exist are individuals like Dr. Howe who practiced prior to rgr4. There are certainly none since then.

We in medicine have been completely insulated from this problem. ...

[The physicians at Lexington and Fort Worth] only have a single facet of this problem at their command, that of the detoxification of the patient, removing him from the drugs. But as fine as these gentlemen are, they are not seeing the drug addict in his own environment, which produced the addiction in the first place. They see him in a highly artificial environment, in a drug-free environment, which is what these hospitals should be and usually are.

If this point is valid, then the question becomes one of the conditions under which provision could be made for a satisfactory physician-patient relationship for the treatment of addiction within the community. In view also of the low level of success hitherto achieved in the cure of addiction, it is clear that such provision would have to allow for the continuation of a therapeutic relationship, despite the success or failure of the treatment, for a sufficient length of time to permit physicians to achieve a thorough familiarity with the problem of addiction in its natural setting.

The other point to be raised about the medical perspective deals with the applicability to the young addict of the psychiatrist's conception of addiction as a symptom of personality defect or his conception of the addict as a "sick person." Conflicting interpretations of the nature of addiction among young persons have been advanced by Ausubel and Pfeffer. Starting from the assumption that the use of drugs by young persons has not generally been attributable to the existence of special personality defect, Ausubel reasons that in such cases the addiction has not been adjustive and, therefore, should prove to be transitory: ${ }^{25}$ addicts. ...

.... Actually, only a very small proportion of these new cases are true or permanent

The vast majority of our recent new adolescent cases . . . are pseudo or transitory addicts. Drug addiction has no real adjustive value for them....

The "experimental" form of drug addiction in contrast to the adjustive type that depends on a special personality defect, is a transitory, self-limited phenomenon which leaves no serious or lasting consequences.

Adopting another point of view is Pfeffer, who has the following to say about the treatability of the adolescent addict: ${ }^{26}$

I am quite in agreement with those who have seen a good many of the adolescent addicts ... and who feel that the adolescent is more difficult to treat than the adult.

The mere fact of such disagreement between two psychiatrists suggests that legitimate question can be raised about the applicability of a conception of personality defect as a necessary condition for all cases of addiction among young persons. Although it is an impression that cannot be documented, it appears that very few of

${ }^{25}$ Ausubel, An Evaluation of Recent Drug Addiction, 36 MENTAL HygIENE 374, 375 (1952).

${ }^{20}$ Remarks made in the discussion following Dumpson's presentation of his paper, stipra note 12, at 335 . 
the young persons addicted during the postwar period have subsequently abstained from the use of opiates. There is, therefore, little to suggest that addiction is transitory merely because of the youth of the addict. Nevertheless, since there is little knowledge of the conditions under which addiction can be cured, Ausubel's assumption that many young drug users are not characterized by a special personality defect may still be valid.

The issue raised by the young addict, therefore, and one that can only be answered through further carefully designed studies, is the extent to which the "sick person" concept of addiction that has been advanced by psychiatrists is applicable to the recent manifestation of the problem. Several aspects of the study reported here cast doubt upon its tenability. Many influences with their origins in the total social milieu of the young addict appear to have converged and to have facilitated the spread of narcotics use. The high concentration of these users within a few disadvantaged areas with very special characteristics is not accompanied by any evidence of a similar concentration of personality defects among young persons. This statement, however, is not to be taken as implying a denial of the operation of selective factors. The spread of fashion and fashion-like movements is apparently always accompanied by selective involvement and varying degrees of commitment on the part of different persons. As a type of fashion-like collective movement, the use of heroin has been no exception. However, the nature of these selective forces cannot be assumed to be known on an a priori basis before actual empirical investigation of the problem.

This matter has been dealt with at this length, because it is central to any conception of the treatability of the young addict who is still close to the milieu in which he originally became a narcotics user and because his youth itself poses a challenge to all who would assist him. Clearly no advance in the treatment of addiction can be expected until more valid conceptions of the physiological, psychological, and sociological aspects of addiction are developed.

In conclusion, the limitations of both the correctional and the medical approaches, particularly as applicable to the young addict, should be recognized. They have both, hitherto, been restricted to dealing with the addict in institutional situations; they have both assumed a conception of addiction which attributes its etiology almost solely to factors either inherent within or expressive of the individual's make-up or problems. This paper has been written in the belief that each of these perspectives requires reappraisal in the light of the problem of the young addict, and that it is only as these perspectives become modified so as to be able to deal with addiction as an aspect of a special type of community setting with a particularly destructive impact on its young persons, that any headway can be gained in coping with the problem of addiction. 